\title{
Distinct prognostic value of mRNA expression of guanylate-binding protein genes in skin cutaneous melanoma
}

\author{
QIAOQI WANG ${ }^{1}$, XIANGKUN WANG ${ }^{2}$, QIAN LIANG $^{1}$, SHIJUN WANG $^{3}$, \\ LIAO XIWEN ${ }^{2}$, FUQIANG PAN ${ }^{1}$, HONGYANG CHEN ${ }^{1}$ and DONG LI ${ }^{1}$ \\ ${ }^{1}$ Cosmetic and Plastic Center, The Second Affiliated Hospital of Guangxi Medical University, Nanning, Guangxi 530000; \\ ${ }^{2}$ Department of Hepatobiliary Surgery, The First Affiliated Hospital of Guangxi Medical University, Nanning, \\ Guangxi 530021; ${ }^{3}$ Department of Colorectal and Anal Surgery, The First Affiliated Hospital of Zhengzhou University, \\ Zhengzhou, Henan 450000, P.R. China
}

Received September 21, 2017; Accepted March 14, 2018

DOI: $10.3892 / \mathrm{ol} .2018 .8306$

\begin{abstract}
The purpose of the present study was to assess if guanylate-binding protein (GBP) mRNAs could be prognostic biomarkers for patients with skin cutaneous melanoma (SKCM). The prognostic value of GBP mRNA expression in patients with SKCM was investigated by analyzing gene expression data in 459 SKCM patients. The data were extracted from the OncoLnc database of The Cancer Genome Atlas. A high expression of $G B P 1, G B P 2, G B P 3, G B P 4$ and $G B P 5$ were correlated with favorable overall survival (OS) in the SKCM patients followed for over 30 years. In addition, a high expression of GBP6 mRNA was not correlated with OS in the SKCM patients. A joint effects analysis showed that the co-incidence of the high expression of GBP1-5 was correlated with favorable overall survival in SKCM patients. Our findings suggest that GBP1-5 mRNAs in SKCM are associated with favorable prognosis and may be potential prognostic biomarkers. The combination of GBPl-5 could improve the sensitivity for predicting OS in SKCM patients.
\end{abstract}

\section{Introduction}

Skin cutaneous melanoma (SKCM) is one of the most aggressive malignancies; tumors of millimeters are lethal. SKCM accounts for $91 \%$ of new cases of skin cancers and results in $74 \%$ of skin-related deaths (1). The incidence of SKCM has continued to increase in recent years, and it tends

Correspondence to: Professor Dong Li, Cosmetic and Plastic Center, The Second Affiliated Hospital of Guangxi Medical University, 116 Daxue East Road, Nanning, Guangxi 530000, P.R. China

E-mail: 1d_gxykdx@hotmail.com

Abbreviations: GBP, guanylate-binding protein; OS, overall survival; SKCM, skin cutaneous melanoma

Key words: guanylate-binding protein, mRNA, correlation, prognosis to affect younger people $(1,2)$. The 5 -year and 10 -year relative survival rates for persons with SKCM are 92 and $89 \%$, respectively. The primary treatment for SKCM is surgery combined with chemotherapy, immunotherapy and radiation (3). Effective prognosis markers may aid in therapeutic treatment for SKCM patients (4). Previous studies have shown that many genes, including $A U R K B, C C N E 1, C D C A 8$, CDK4, CENPO, GINS2, H2AFZ, LIG1, PKMYT1, PLK1, PTTG1, SKA1, TUBA1B, TUBA1C, TYMS (5), and EZH2 (6), are associated with poor prognosis in SKCM. However, the association between GBP genes and the prognosis of SKCM has not been reported.

Guanylate-binding protein (GBP) belongs to the superfamily of INF-inducible guanosine triphosphate hydrolases (GTPases) (7,8). Up to now, seven human GBP genes, including guanylate-binding protein 1 (GBPl), guanylate-binding protein 2 (GBP2), guanylate-binding protein 3 (GBP3), guanylate-binding protein 4 (GBP4), guanylate-binding protein 5 (GBP5), guanylate-binding protein family member 6 (GBP6) and guanylate-binding protein 7 (GBP7), have been reported (9-11). GBPs, such as $G B P 1$ and $G B P 2$, have antiviral and antimicrobial activities in host defense (12) and could act as protective factors in host defense, controlling infection and autoimmunity (13).

The roles of $G B P$ genes in cancers are complicated. Studies showed that some GBP family members were expressed in colorectal cancer (CRC) (14-17), breast cancer $(18,19)$, oral squamous cell carcinoma (OSCC) (20), esophageal squamous cell carcinomas (SCC) (21), cutaneous T-cell lymphoma (22), prostate cancer (23), and Kaposi's sarcoma $(24,25)$. GBPl was upregulated in CRC (15) and OSCC (20), modulated the migration and invasion of OSCC cell in vitro (20), and inhibited the growth of highly malignant TS/A mammary carcinoma cells $(19)$ and CRC tumors $(14,15,17)$ in vivo. The high expression of $G B P 1$ was associated with high overall pathological stage in OSCC tissue. GBP2 was related to T-cell infiltration in breast cancer (18).

The expression of GBP mRNAs is highly induced by interferon- $\gamma$ (IFN- $\gamma$ ) in many cells including fibroblasts, B cells, T cells, and some tumor cells $(15,24,26)$. $G B P$ was also associated with the prognosis of many 
cancers $(14,16-21,23,25)$. In addition, $G B P 1$ plays dual roles in different tumor cells. Upregulated $G B P 1$ mediated the anti-tumorigenic effects of IFN- $\gamma$ and correlated with better OS in CRC $(15,17)$. However, overexpressed GBPI was significantly associated with poorer prognosis in OSCC patients (20). A high expression of GBP2 with a favorable prognosis was found in patients with node-negative breast carcinomas (18). However, the prognostic value of individual $G B P$ in SKCM remains elusive. The present study investigated the prognostic value of individual $G B P$ mRNA and made a joint effects analysis in 459 SKCM patients using OncoLnc data generated from The Cancer Genome Atlas (TCGA; https://cancergenome.nih.gov/, accessed March 1, 2017) database (27). Our results indicated that a high mRNA expression of individual GBPl-5 genes and a high co-expression of these gene mRNAs were correlated with high OS, suggesting that these genes may be potential prognosis biomarkers in SKCM patients.

\section{Materials and methods}

Data preparation. TCGA survival data of SKCM was extracted from OncoLnc (http://www.oncolnc.org/, accessed March 3, 2017) (27), including the patients' ID in TCGA, sex, age at diagnosis, events, median survival, survival time, death status, and $G B P$ members' mRNA expression regarding 459 SKCM patients. Briefly, 7 GBP sub-members ( $G B P 1$, GBP2, GBP3, GBP4, GBP5, GBP6, and GBP7) were entered into the database (http://www.oncolnc.org/, accessed by March $3,2017)$. The patients were sorted into a percentile of 50:50 by the expression of every GBP sub-member, and then SKCM patients' survival data information was obtained.

The Metabolic gEne RApid Visualizer (MERAV: http://merav.wi.mit.edu/SearchByGenes.html, accessed March 1, 2017) (28) was used to make a boxplot of $G B P$ sub-members' expression levels in normal tissue and primary tumors of skin cancer. After $G B P$ genes and the selected tissue type were submitted on the website, boxplots were made and displayed. The unit for mRNA expression is counted in downloaded TCGA data.

Correlation and bioinformatics analysis. The Pearson correlation coefficient was used to assess the co-expression of $G B P$ genes. The relative expression levels of $G B P$ genes in multiple normal tissues were determined with the GTEx Portal (http://www.gtexportal.org/home/, accessed April 25, 2017) (29). A gene function prediction website (GeneMANIA: http://genemania.org/, accessed March 15, 2017) (30) was also used to construct the gene-gene interaction networks. The Database for Annotation, Visualization, and Integrated Discovery (DAVID) v.6.7 (https://david. ncifcrf.gov/tools.jsp, accessed April 3, 2017) (31,32) was used to annotate input genes, classify gene functions, identify gene conversions, and carry out Gene Ontology (GO) term analysis (32). $\mathrm{P}<0.05$ and a false discovery rate (FDR) $<0.05$ were considered to indicate a statistically significant difference.

Survival analysis. A Kaplan-Meier estimator with a log-rank test was used to evaluate the correlation of six mRNAs with patient survival. Hazard ratios (HR) and 95\% confidence intervals $(\mathrm{CI})$ were used to assess the relative risk of SKCM survival.

Joint effects analysis. A joint effects analysis was performed based on the survival analysis results. Patients were regrouped based on the combined GBP mRNA expression and OS scores, which were calculated by summarizing all of the points given to GBPl-5 in a patient when 1 point was assigned to genes of high expression with favorable OS and 0 points were assigned to genes of low expression with poor OS.

Statistical analysis. Statistical analyses were carried out using SPSS v.22.0 software (IBM, Chicago, IL, USA). P<0.05 was considered to indicate a statistically significant difference.

\section{Results}

mRNA expression of GBP genes in human normal skin and skin cancer tissues. The GBP family is composed of seven members. Among the seven $G B P$ genes, only $G B P 7$ was not found in www.oncolnc.org, likely due to its low expression (33). In human skin tissue, GBP2 and GBP6 were expressed at high levels, whereas the remaining $G B P$ genes ( $G B P 1, G B P 3, G B P 4$ and $G B P 5$ ) were expressed at low levels (Fig. 1A-F; Fig. 1A, GBP1; Fig. 1B, GBP2; Fig. 1C, GBP3; Fig. 1D, GBP4; Fig. 1E, GBP5; Fig. 1F, GBP6).

The boxplots of the $G B P$ family generated from MERAV shows differences in the expression levels of $G B P$ genes between normal skin tissue and primary skin tumor. The expressions of $G B P 1, G B P 4$ and GBP5 in normal skin tissue were higher than skin cancer. Moreover, the expressions of $G B P 2, G B P 3$ and GBP6 in skin cancer were higher than in normal skin tissue (Fig. 2).

Functions and correlation of the mRNA expression of GBP genes in human tissues. A co-expression analysis (Fig. 3) showed that $G B P 1, G B P 2, G B P 3, G B P 4$ and $G B P 5$ were co-expressed in human tissues. GBP3 was in the NFATC2 pathway, GBP2 was in the IFI35, IRF9 and XAF1 pathways, and GBP2 was predicted in the IRFI pathway. The correlation of individual GBP family gene mRNA expression was tested using the Pearson correlation coefficient (Table I). With the exception of $G B P 6$, the mRNA expression of all other $G B P$ family genes was significantly $(\mathrm{R}=0.550-0.842, \mathrm{P}<0.001)$ positively correlated (Table I). A GO term analysis using DAVID revealed that $G B P$ genes were significantly associated with the biological process of immune response, as well as the molecular functions of GTPases activity and guanosine triphosphate (GTP) binding (Table II).

Survival analysis. The prognostic value of the GBP family gene mRNA expression was assessed with SPSS. A high expression of $G B P 1-5$ was significantly $(\mathrm{P}<0.001)$ associated with a favorable OS in SKCM patients (Fig. 4A-E). GBP6 expression did not show a significant correlation with OS in SKCM patients $(\mathrm{P}=0.401925, \mathrm{HR}=1.121,95 \% \mathrm{CI}=0.8580-1.465)$ (Fig. 4F).

Joint effects analysis. A joint effects analysis was used to determine the combined effect of the GBP gene mRNA 
A

GBP1 Gene Expression

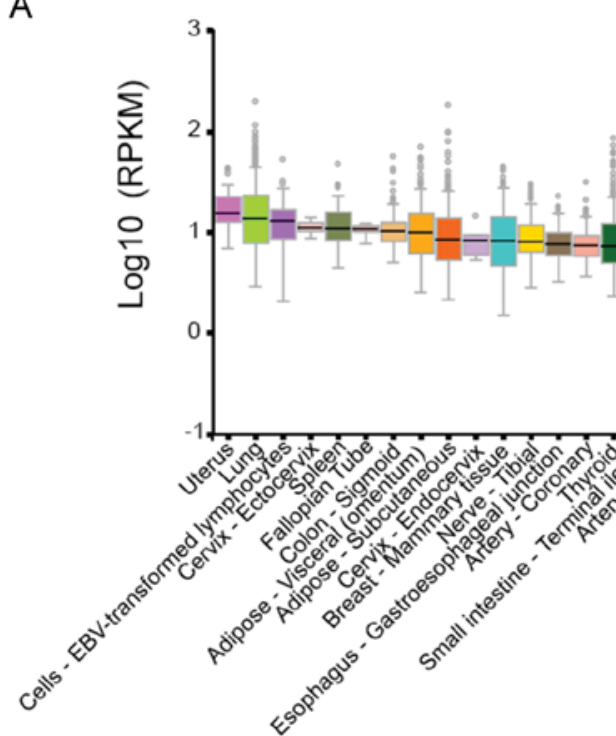

B

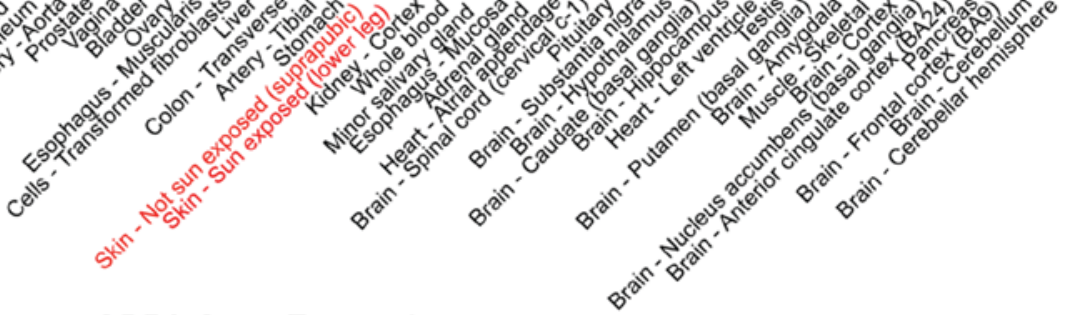

GBP2 Gene Expression

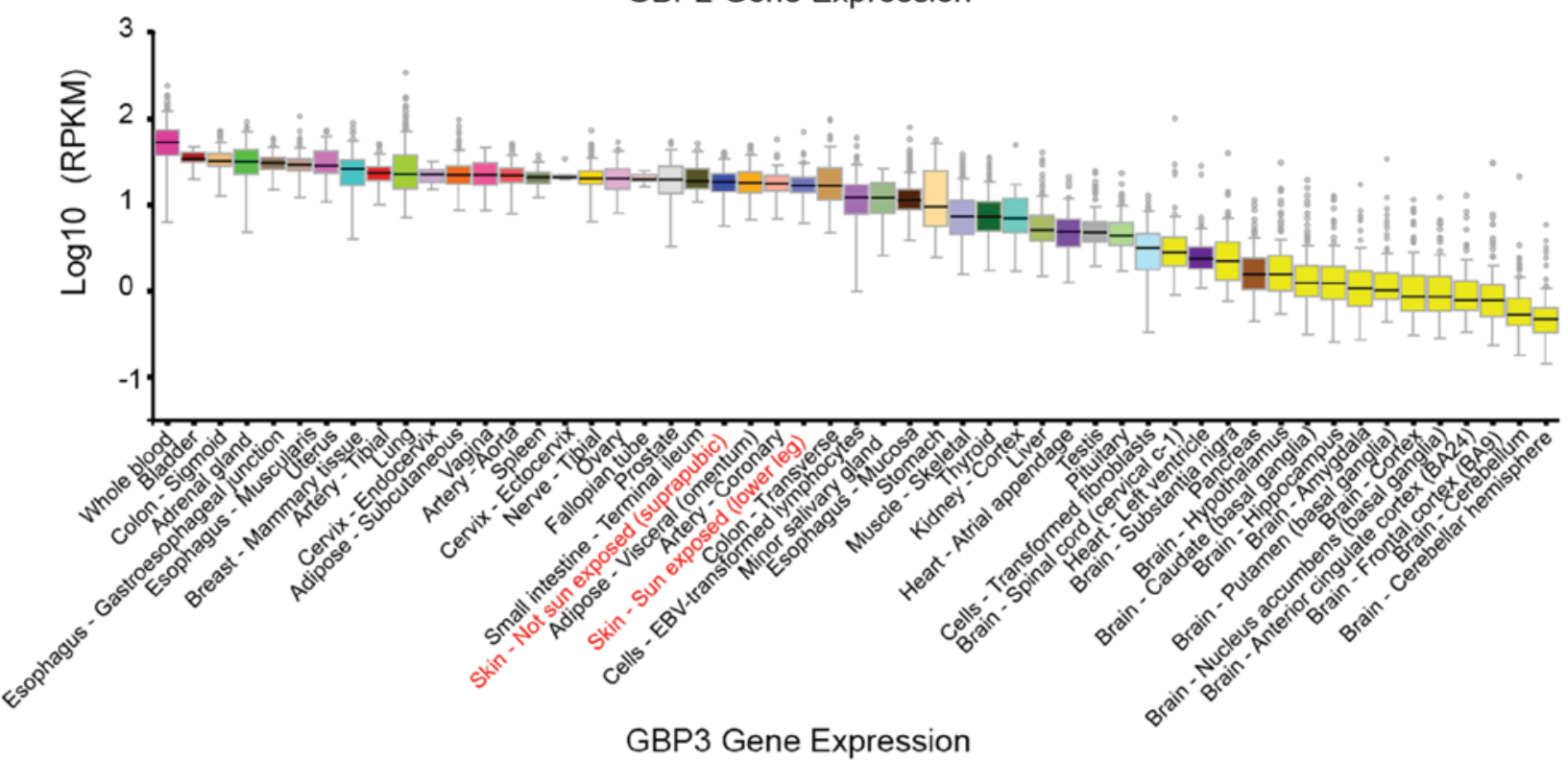

C

GBP3 Gene Expression

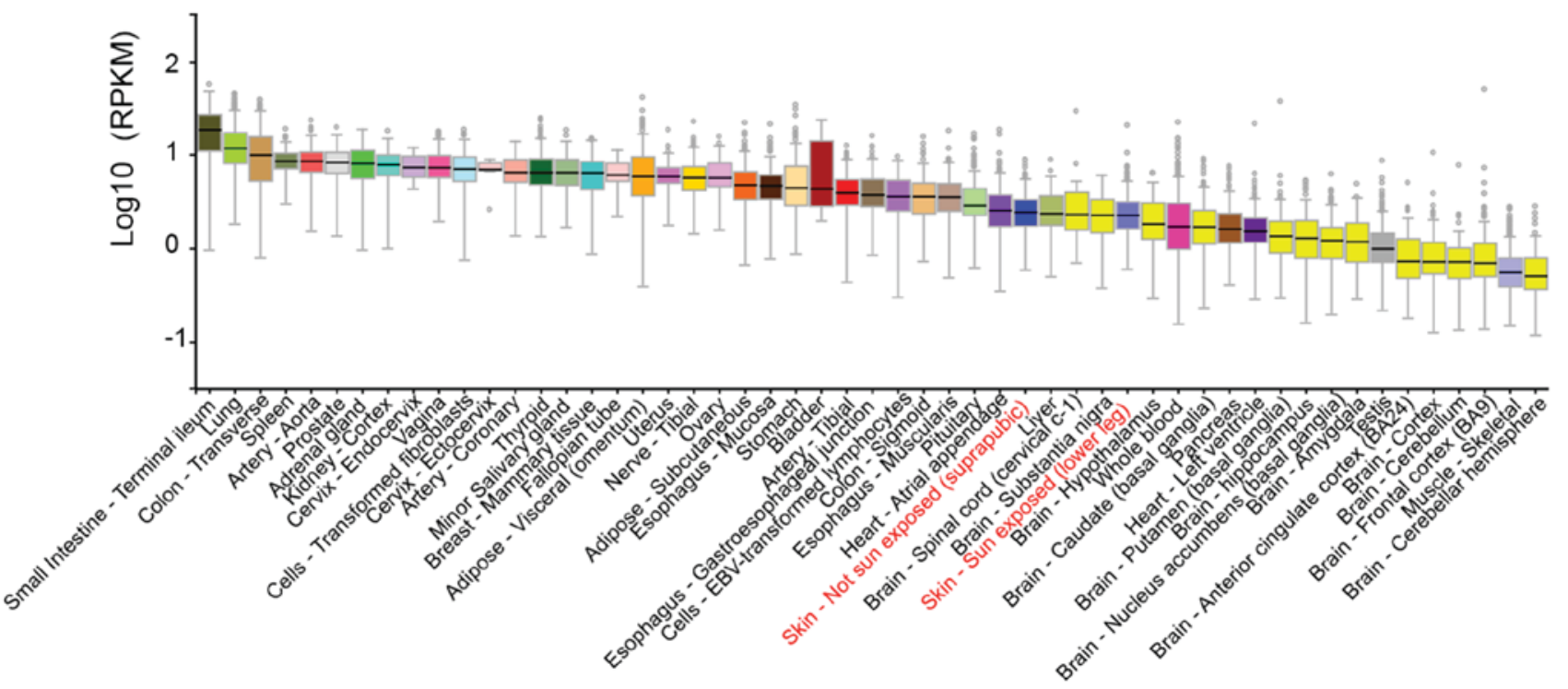

Figure 1. GBP genes in multiple normal tissues in the GTEx Portal database. The expression of $G B P$ genes in normal skin tissue was highlighted in red. (A) $G B P 1$ gene expression in multiple normal tissues; (B) GBP2 gene expression in multiple normal tissues; (C) GBP3 gene expression in multiple normal tissues. GBP, guanylate-binding protein. 


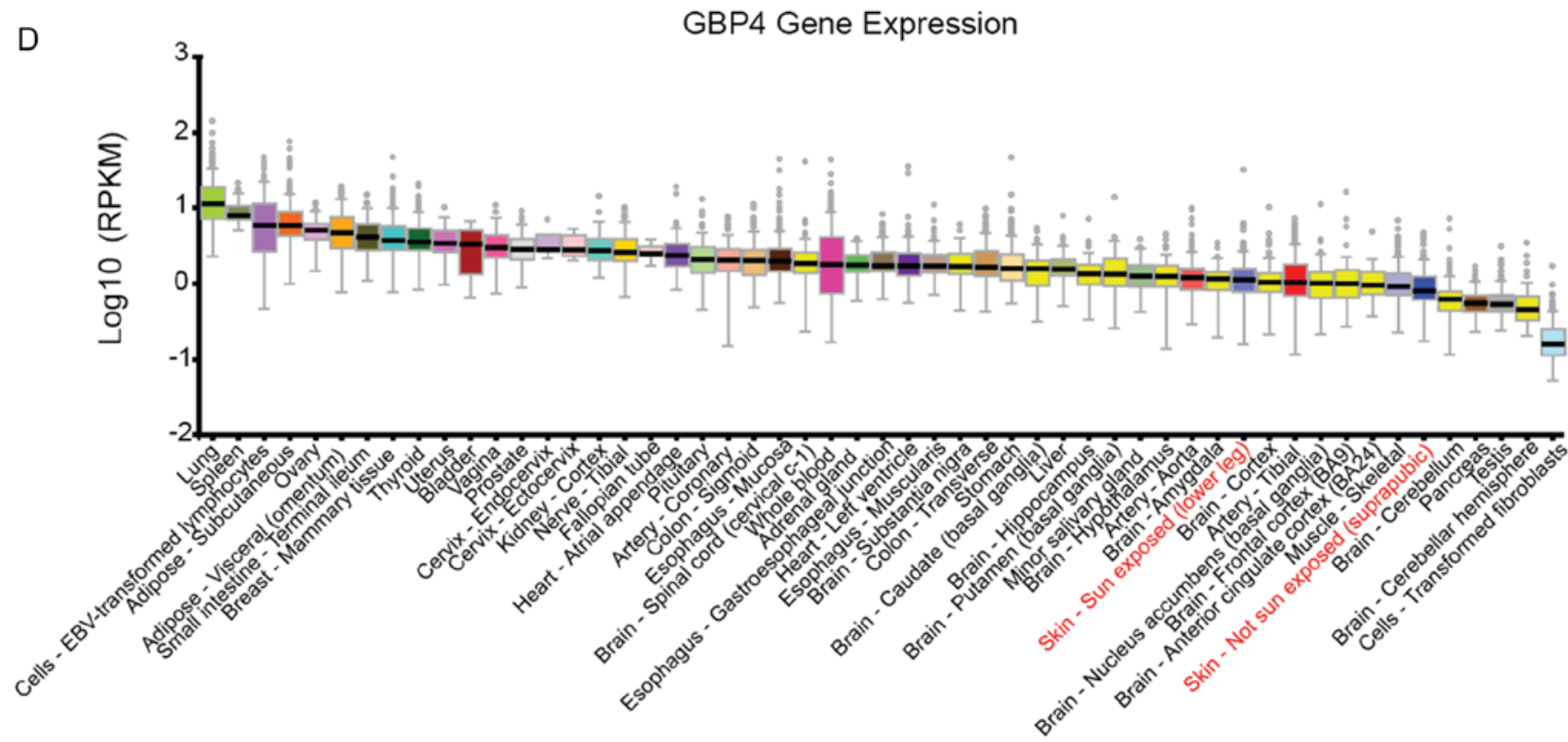

E

GBP5 Gene Expression

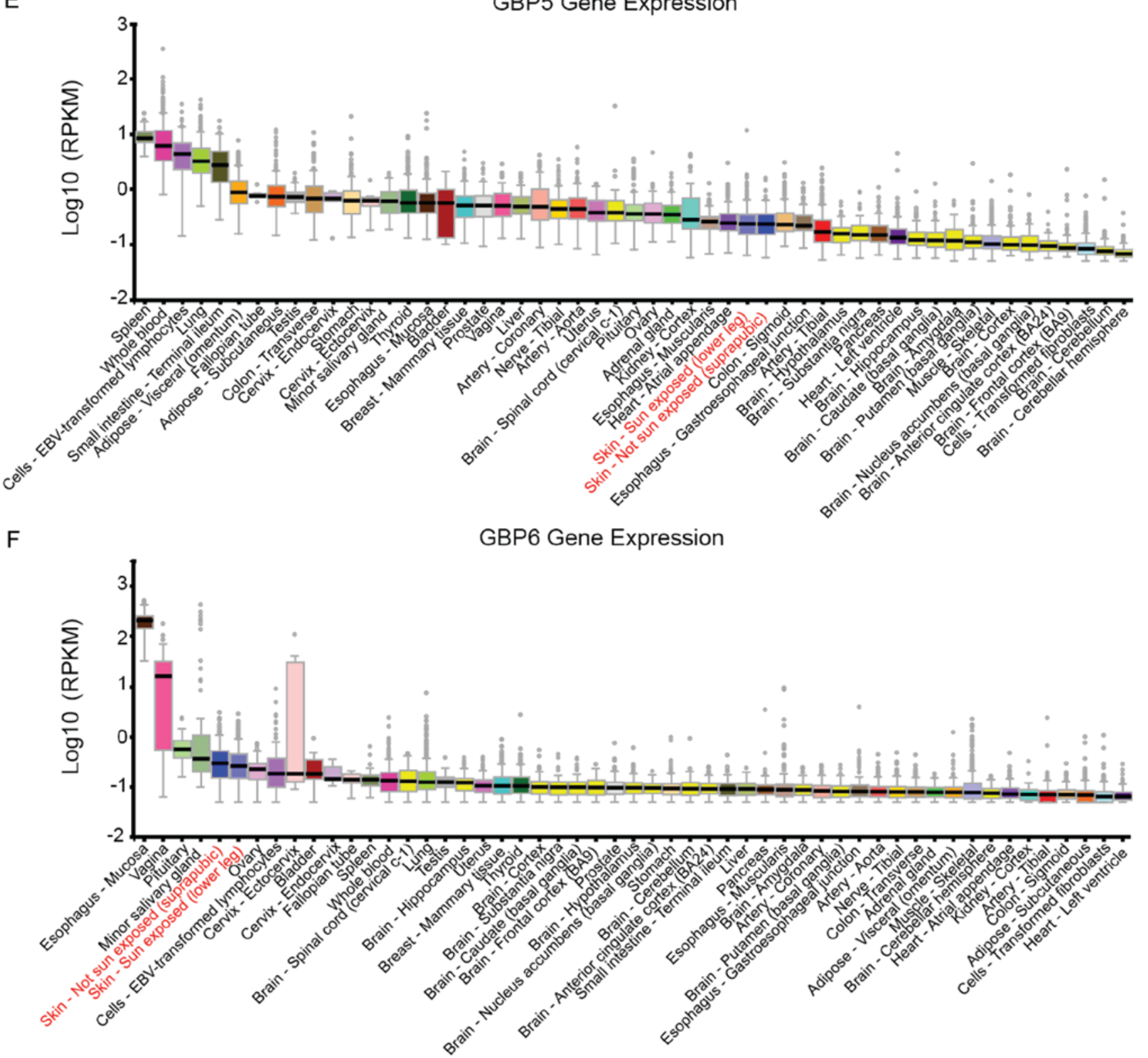

Figure 1. Continued. (D) GBP4 gene expression in multiple normal tissues; (E) GBP5 gene expression in multiple normal tissues; (F) GBP6 gene expression in multiple normal tissues. GBP, guanylate-binding protein. 
A

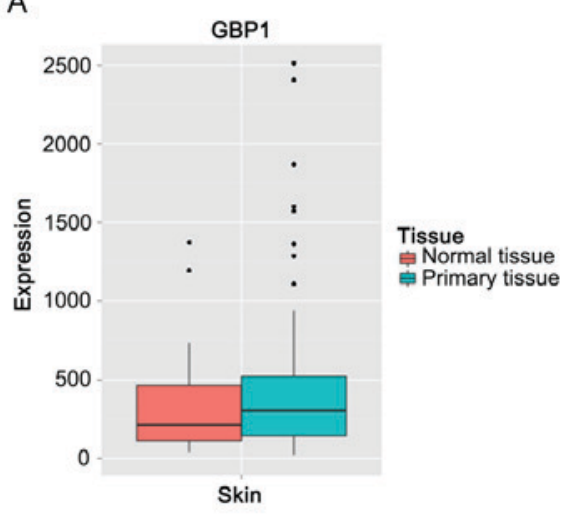

D

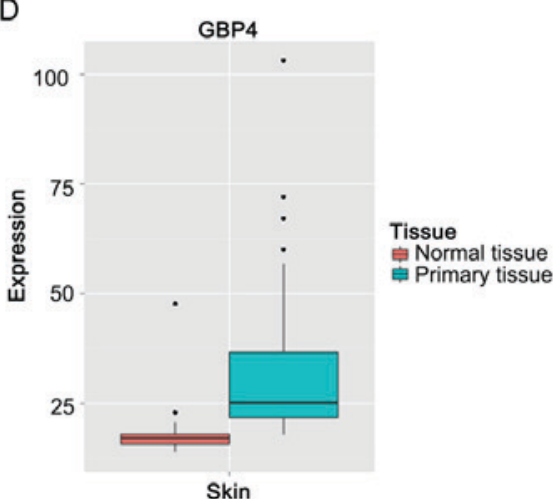

B
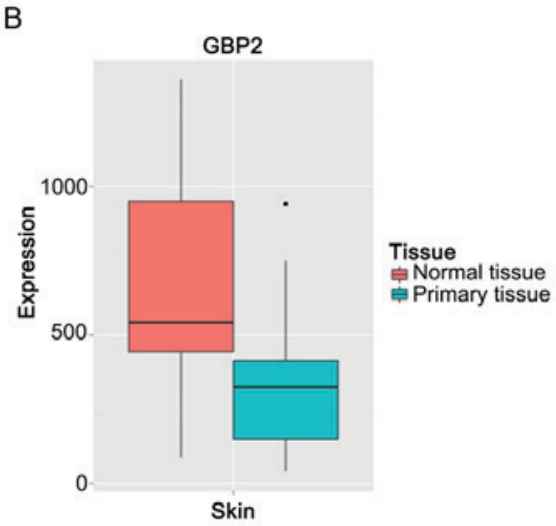

$\mathrm{E}$

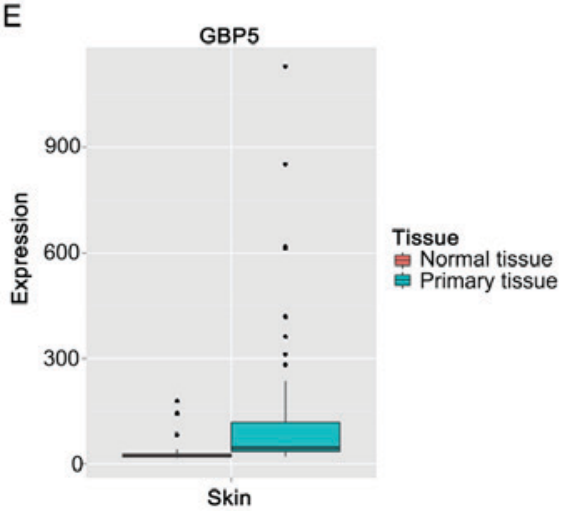

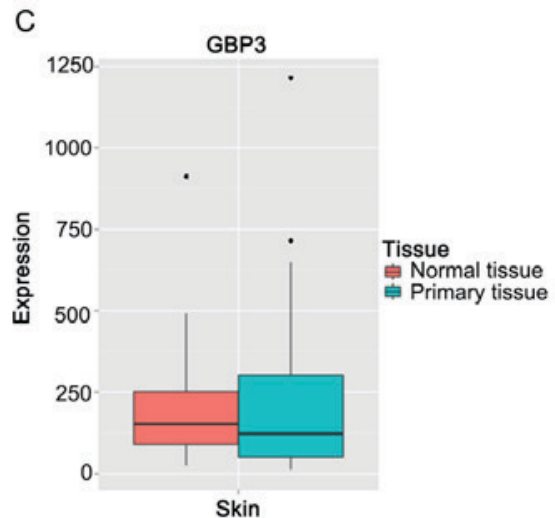

$\mathrm{F}$

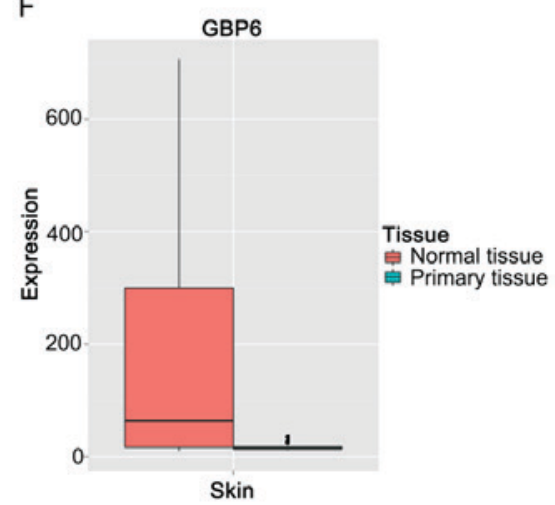

Figure 2. The MERAV boxplots of $G B P$ family expression in skin normal tissue and primary tumor. (A) Boxplot for $G B P 1$ expression; (B) boxplot for $G B P 2$ expression; (C) boxplot for GBP3 expression; (D) boxplot for GBP4 expression; (E) boxplot for GBP5 expression; (F) boxplot for GBP6 expression. MERAV, Metabolic gEne RApid Visualizer; GBP, guanylate-binding protein.

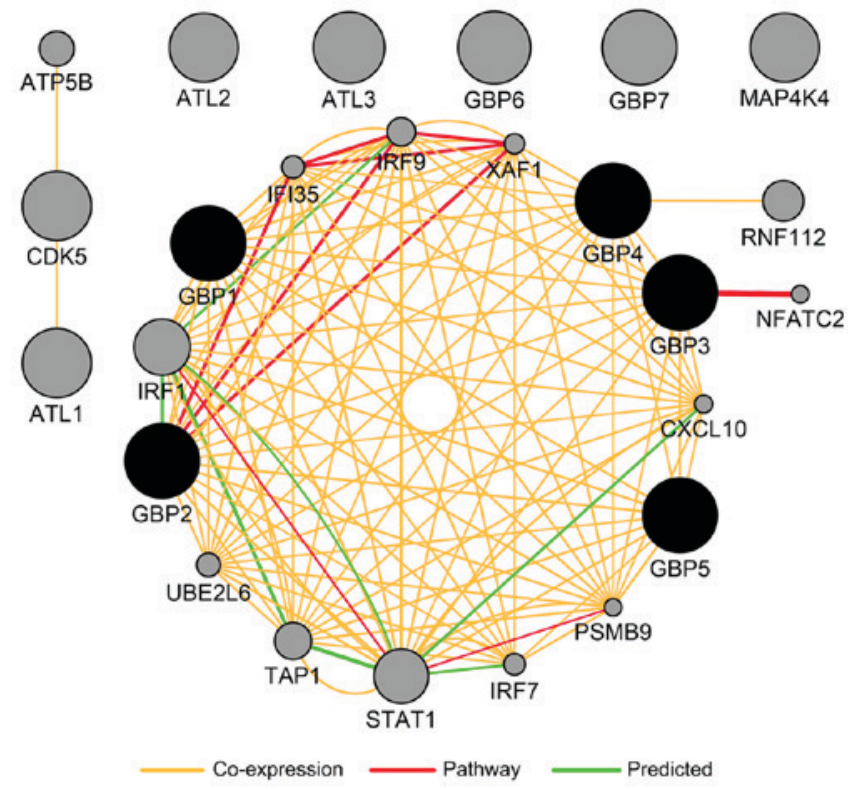

Figure 3. Co-expression/pathway/predication analysis of GBP1, GBP2, GBP3, GBP4 and GBP5 according to human expression data in GeneMANIA. GBP, guanylate-binding protein.

co-expression on the OS of SKCM patients. Patients were divided into 6 groups: Group 1 ( 0 points group, $n=136$ ), group 2 ( 1 point group, $n=60$ ), group 3 ( 2 points group, $n=32$ ), group 4 ( 3 points group, $n=39$ ), group 5 (4 points group, $\mathrm{n}=47$ ) and group 6 (5 points group, $\mathrm{n}=141)$ (detailed grouping information is shown in Table III). Kaplan-Meier estimator with a log-rank test was used to evaluate the prognostic value of these 6 groups. The co-overexpression of GBP1-5 in Group 6 (141 from 455) was found to be more highly correlated with a favorable $\mathrm{OS}$ than the co-overexpression of fewer $G B P$ 
Table I. Co-expression of GBP family at mRNA level.

\begin{tabular}{|c|c|c|c|c|c|c|c|c|c|c|c|c|}
\hline \multirow[b]{2}{*}{ Genes } & \multicolumn{2}{|c|}{$G B P 1$} & \multicolumn{2}{|c|}{$G B P 2$} & \multicolumn{2}{|c|}{$G B P 3$} & \multicolumn{2}{|c|}{$G B P 4$} & \multicolumn{2}{|c|}{ GBP5 } & \multicolumn{2}{|c|}{ GBP6 } \\
\hline & $\mathrm{R}$ & P-value & $\mathrm{R}$ & P-value & $\mathrm{R}$ & P-value & $\mathrm{R}$ & P-value & $\mathrm{R}$ & P-value & $\mathrm{R}$ & P-value \\
\hline GBP1 & - & - & 0.842 & $<0.001$ & 0.743 & $<0.001$ & 0.670 & $<0.001$ & 0.702 & $<0.001$ & 0.000 & 0.995 \\
\hline GBP2 & 0.842 & $<0.001$ & - & - & 0.685 & $<0.001$ & 0.643 & $<0.001$ & 0.654 & $<0.001$ & 0.047 & 0.313 \\
\hline GBP3 & 0.743 & $<0.001$ & 0.685 & $<0.001$ & - & - & 0.550 & $<0.001$ & 0.594 & $<0.001$ & 0.022 & 0.636 \\
\hline GBP4 & 0.670 & $<0.001$ & 0.643 & $<0.001$ & 0.550 & $<0.001$ & - & - & 0.768 & $<0.001$ & -0.013 & 0.776 \\
\hline GBP5 & 0.702 & $<0.001$ & 0.654 & $<0.001$ & 0.594 & $<0.001$ & 0.768 & $<0.001$ & - & - & 0.001 & 0.990 \\
\hline GBP6 & 0.000 & 0.995 & 0.047 & 0.313 & 0.022 & 0.636 & -0.013 & 0.776 & 0.001 & 0.990 & - & - \\
\hline
\end{tabular}

The correlations of gene mRNA expression in $G B P$ families were tested using the Pearson correlation coefficient. R, Pearson correlation coefficient; $G B P$, guanylate-binding protein.

Table II. Analysis of enriched GO terms for GBP genes carried out using DAVID.

\begin{tabular}{lllcc}
\hline Category & \multicolumn{1}{c}{ Term } & Genes & P-value & FDR \\
\hline Molecular function & GTPase activity & 6 & $1.08 \times 10^{-09}$ & $5.58 \times 10^{-07}$ \\
& GTP binding & 6 & $1.88 \times 10^{-08}$ & $9.70 \times 10^{-06}$ \\
& Guanylate nucleotide binding & 6 & $2.15 \times 10^{-08}$ & $1.11 \times 10^{-05}$ \\
& Guanylate ribonucleotide binding & 6 & $2.15 \times 10^{-08}$ & $1.11 \times 10^{-05}$ \\
& Ribonucleotide binding & 6 & $5.63 \times 10^{-05}$ & 0.029018 \\
& Purine ribonucleotide binding & 6 & $5.63 \times 10^{-05}$ & 0.029018 \\
& Purine nucleotide binding & 6 & $7.01 \times 10^{-05}$ & 0.03611 \\
& Nucleotide binding & 6 & $1.54 \times 10^{-04}$ & 0.079382 \\
Biological process & Immune response & 6 & $3.40 \times 10^{-07}$ & $7.69 \times 10^{-05}$ \\
Cellular component & Internal side of plasma membrane & 3 & 0.001798 & - \\
& Plasma membrane part & 3 & 0.078854 & - \\
& Plasma membrane & 3 & 0.210327 & - \\
\hline
\end{tabular}

GBP, guanylate-binding protein; GO Gene Ontology; DAVID, Database for Annotation, Visualization, and Integrated Discovery; GTPases, guanosine triphosphates. GTP, guanosine triphosphate; FDR, false discovery rate.

genes in other groups $(\mathrm{P}<0.0001)$. In contrast, the expression of GBPs was homogeneously low in Group 1 (136 from 455), which was found to be more highly correlated with poor OS than the other groups $(\mathrm{P}<0.0001)$ (Fig. 5).

\section{Discussion}

In the present study, the data for the GBP gene mRNA expression and survival of SKCM patients were extracted from OncoLnc, analyzed to predict the function of $G B P$ genes, and assessed for the potential of the mRNA expression of $G B P$ genes to be used as prognosis biomarkers. Our analysis revealed that GBPs may be responsible for host defense, GTP binding and GTP hydrolysis. The correlation between the GBP gene mRNA levels and OS suggested that $G B P$ mRNA may be good prognosis biomarkers for SKCM patients.

Our bioinformatics analysis revealed that the most meaningful molecular functions of GBP were GTPase activity, GTP binding, guanylate nucleotide binding, guanylate ribonucleotide binding, ribonucleotide binding, purine ribonucleotide binding, purine nucleotide binding, and nucleotide binding, which is in agreement with the observations that GBP belongs to the superfamily of INF-inducible GTPases including four sub-families: GBPs, immunity-related GTPases, very large inducible GTPase and myxovirus resistance proteins $(7,8)$. The probable involvement of GBPs in the biological process of immunity deduced by our analysis is in agreement with the observations that GBPs, such as GBP1 and GBP2, have antiviral and antimicrobial activities in host defense (12) and that GBPs could act as protective factors in host defense, controlling infection and autoimmunity (13). The predicted immunity roles of $G B P$ genes are also in agreement with the finding that upregulated $G B P 1$ in CRC inhibits tumor growth $(14,15,17)$ and that $G B P 2$ was associated with T-cell infiltration in breast cancer (18).

In the present study, the Kaplan-Meier curves show that a high expression of GBPl-5 was found to be correlated with favorable OS in all SKCM patients. The correlation between a 

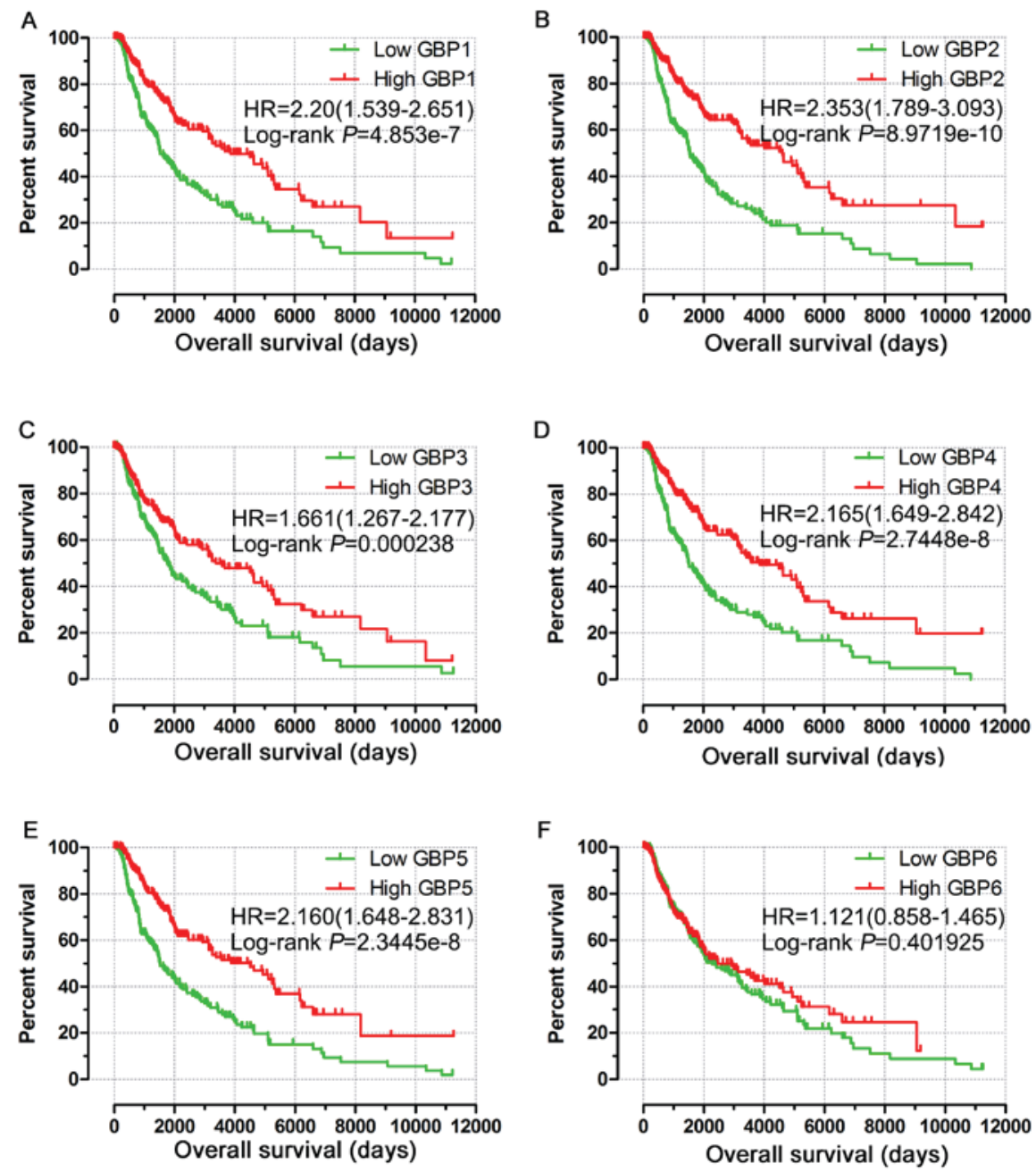

Figure 4. The prognostic value of $G B P$ expression. (A) survival curves are plotted for all SKCM patients of $G B P 1$ (n=458); (B) survival curves are plotted for all SKCM patients of GBP2 ( $\mathrm{n}=458)$; (C) survival curves are plotted for all SKCM patients of $G B P 3(\mathrm{n}=458)$; (D) survival curves are plotted for all SKCM patients of GBP4 (n=458); (E) survival curves are plotted for all SKCM patients of GBP5 (n=458); (F) survival curves are plotted for all SKCM patients of GBP6 (n=458). Data were analyzed using SPSS. GBP, guanylate-binding protein; SKCM, skin cutaneous melanoma.

high expression of GBP1 and favorable OS in SKCM patients is in accordance with its correlation with high survival in CRC (17) but contrary to its correlation with poor survival in OSCC (20). These results indicated that GBPI could play different roles in different cancers. The correlation of a high expression of GBP2 with a favorable OS in SKCM observed in the present study and in node-negative breast carcinomas (18) suggests that $G B P 2$ may share the same mechanism in both SKCM and node-negative breast carcinomas. Though the expression of GBP6 in skin tumor tissue was more than its expression in normal tissue, no correlation between prognosis value with high expression of $G B P 6$ or low expression of $G B P 6$ was found. It is unclear why the high expression of downregulated $G B P 1, G B P 4$ and $G B P 5$, as well as upregulated $G B P 2$ and $G B P 3$ showed the same correlation with a favorable OS in skin cancer. No survival information on GBP7 in SKCM patients is available, likely due to its low expression in normal skin tissue and SKCM, which makes it difficult to assess its correlation with prognosis outcomes.

The joint effects analysis showed that the co-expression of GBPI-5 all at high levels was correlated with a favorable OS in SKCM patients. In contrast, the co-expression of

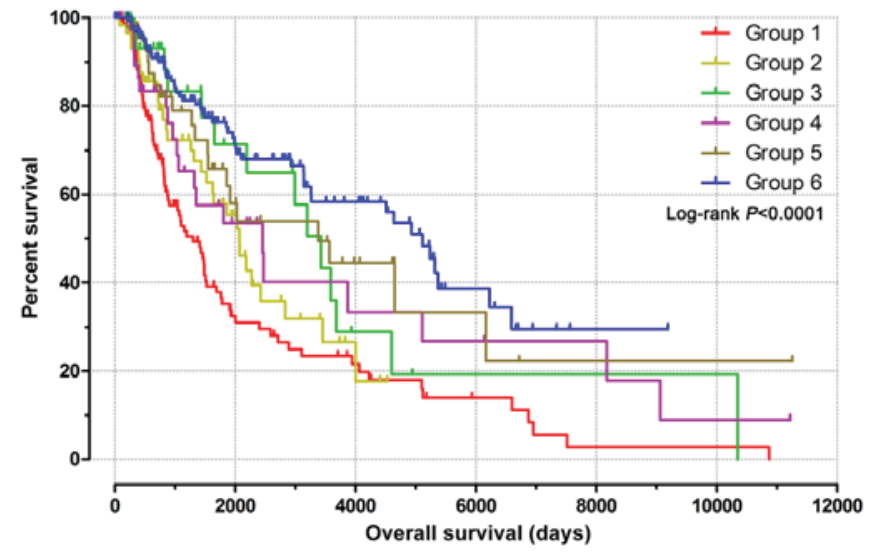

Figure 5. The result of the joint effects analysis. OS stratified by 5 GBP genes expression levels. Group 1 ( 0 points group, $\mathrm{n}=136$ ), Group 2 (1 point group, $\mathrm{n}=60$ ), Group 3 ( 2 points group, $\mathrm{n}=32$ ), Group 4 ( 3 points group $\mathrm{n}=39$ ), Group 5 (4 points group, $\mathrm{n}=47$ ) and Group 6 (5 points group, $\mathrm{n}=141$ ). GBP, guanylate-binding protein.

GBP1-5 at low levels was correlated with poor OS in SKCM patients. There was a tendency for GBP genes with higher 
Table III. Grouping information for the combination among GBP genes.

\begin{tabular}{|c|c|c|}
\hline Group & Points & Composition \\
\hline 1 & 0 & Low $G B P 1+$ Low $G B P 2+$ Low $G B P 3+$ Low $G B P 4+$ Low $G B P 5$ \\
\hline 2 & 1 & High $G B P 1+$ Low $G B P 2+$ Low $G B P 3+$ Low $G B P 4+$ Low $G B P 5$ \\
\hline 2 & 1 & Low $G B P 1+$ High $G B P 2+$ Low $G B P 3+$ Low $G B P 4+$ Low $G B P 5$ \\
\hline 2 & 1 & Low $G B P 1+$ Low $G B P 2+$ High $G B P 3+$ Low $G B P 4+$ Low $G B P 5$ \\
\hline 2 & 1 & Low $G B P 1+$ Low $G B P 2+$ Low $G B P 3+$ High $G B P 4+$ Low $G B P 5$ \\
\hline 2 & 1 & Low $G B P 1+$ Low $G B P 2+$ Low $G B P 3+$ Low $G B P 4+$ High $G B P 5$ \\
\hline 3 & 2 & High $G B P 1+$ High $G B P 2+$ Low $G B P 3+$ Low $G B P 4+$ Low $G B P 5$ \\
\hline 3 & 2 & High $G B P 1+$ Low $G B P 2+$ High $G B P 3+$ Low $G B P 4+$ Low $G B P 5$ \\
\hline 3 & 2 & High $G B P 1+$ Low $G B P 2+$ Low $G B P 3+$ High $G B P 4+$ Low $G B P 5$ \\
\hline 3 & 2 & High $G B P 1+$ Low $G B P 2+$ Low $G B P 3+$ Low $G B P 4+$ High $G B P 5$ \\
\hline 3 & 2 & Low $G B P 1+$ High $G B P 2+$ High $G B P 3+$ Low $G B P 4+$ Low $G B P 5$ \\
\hline 3 & 2 & Low $G B P 1+$ High $G B P 2+$ Low $G B P 3+$ High $G B P 4+$ Low $G B P 5$ \\
\hline 3 & 2 & Low $G B P 1+$ High $G B P 3+$ Low $G B P 3+$ Low $G B P 4+$ High $G B P 5$ \\
\hline 3 & 2 & Low $G B P 1+$ Low $G B P 2+$ High $G B P 3+$ High $G B P 4+$ Low $G B P 5$ \\
\hline 3 & 2 & Low $G B P 1+$ Low $G B P 2+$ High $G B P 3+$ Low $G B P 4+$ High $G B P 5$ \\
\hline 3 & 2 & Low $G B P 1+$ Low $G B P 2+$ Low $G B P 3+$ High $G B P 4+$ High $G B P 5$ \\
\hline 4 & 3 & High $G B P 1+$ High $G B P 2+$ High $G B P 3+$ Low $G B P 4+$ Low $G B P 5$ \\
\hline 4 & 3 & High $G B P 1+$ High $G B P 2+$ Low $G B P 3+$ High $G B P 4+$ Low $G B P 5$ \\
\hline 4 & 3 & High $G B P 1+$ High $G B P 2+$ Low $G B P 3+$ Low $G B P 4+$ High $G B P 5$ \\
\hline 4 & 3 & High $G B P 1+$ Low $G B P 2+$ High $G B P 3+$ High $G B P 4+$ Low $G B P 5$ \\
\hline 4 & 3 & High $G B P 1+$ Low $G B P 2+$ High $G B P 3+$ Low $G B P 4+$ High $G B P 5$ \\
\hline 4 & 3 & High $G B P 1+$ Low $G B P 2+$ Low $G B P 3+$ High $G B P 4+$ High $G B P 5$ \\
\hline 4 & 3 & Low $G B P 1+$ High $G B P 2+$ High $G B P 3+$ High $G B P 4+$ Low $G B P 5$ \\
\hline 4 & 3 & Low $G B P 1+$ High $G B P 2+$ High $G B P 3+$ Low $G B P 4+$ High $G B P 5$ \\
\hline 4 & 3 & Low $G B P 1+$ High $G B P 2+$ Low $G B P 3+$ High $G B P 4+$ High $G B P 5$ \\
\hline 4 & 3 & Low $G B P 1+$ Low $G B P 2+$ High $G B P 3+$ High $G B P 4+$ High $G B P 5$ \\
\hline 5 & 4 & High $G B P 1+$ High $G B P 2+$ High $G B P 3+$ High $G B P 4+$ Low $G B P 5$ \\
\hline 5 & 4 & High $G B P 1+$ High $G B P 2+$ High $G B P 3+$ Low $G B P 4+$ High $G B P 5$ \\
\hline 5 & 4 & High $G B P 1+$ High $G B P 2+$ Low $G B P 3+$ High $G B P 4+$ High $G B P 5$ \\
\hline 5 & 4 & High $G B P 1+$ Low $G B P 2+$ High $G B P 3+$ High $G B P 4+$ High $G B P 5$ \\
\hline 5 & 4 & Low $G B P 1+$ High $G B P 2+$ High $G B P 3+$ High $G B P 4+$ High $G B P 5$ \\
\hline 6 & 5 & High $G B P 1+$ High $G B P 2+$ High $G B P 3+$ High $G B P 4+$ High $G B P 5$ \\
\hline
\end{tabular}

With the median value of the gene expression as cutoff, the patients were designated as high expression or low expression for every member of GBP family, and grouped based on the combination of the gene expression levels. Group 1 (all low expression genes, 0 points group, $\mathrm{n}=136$ ), group 2 ( 1 high expression gene, 1 point group, $n=60$ ), group 3 ( 2 high expression genes, 2 points group, $n=32$ ), group 4 ( 3 high expression genes, 3 points group, $n=39$ ), group 5 (4 high expression genes, 4 points group, $n=47$ ), group 6 (all high expression genes, 5 points group, $\mathrm{n}=141)$. GBP, guanylate-binding protein.

expressions to be more highly correlated with favorable OS. The induced high co-expression of GBPl-5 in cells by IFN- $\gamma(10,34)$ suggests that it may be possible to increase patients' favorable OS through the induction of a higher co-expression of GBP genes with IFN- $\gamma$. This hypothesis needs to be further investigated and experimentally proved. The combination of GBP1-5 may improve the sensitivity of predicting OS in SKCM patients.

There were limitations to the present study that should be recognized. First, since the data from the TCGA database and
OncoLnc was not comprehensive, the present study evaluated the association between gene expression level and OS based on a log-rank test in Kaplan-Meier analysis. Second, the patients in the present study were exclusively from a single source, which meant that a multivariate analysis could not be used to validate the results. It is necessary to validate the prognostic value of these genes in patients with SKCM using independent external validation datasets containing complete clinical information. Despite these limitations, our current study was the first to report that the upregulation of the $G B P$ 
genes (GBP1, GBP2, GBP3, GBP4 and GBP5) in SKCM was associated with a favorable prognosis. GBPI-5 may be used as prognostic biomarkers for SKCM patients.

In conclusion, a high expression of $5 G B P$ genes (GBP1, GBP2, GBP3, GBP4 and GBP5) was individually and coincidentally related to a favorable prognosis for SKCM. GBP1-5 may be used as potential prognostic biomarkers for SKCM patients. These results need to be confirmed in further studies.

\section{Acknowledgements}

The authors would like to thank the contributors of OncoLnc for sharing the SKCM survival data on open access.

\section{References}

1. Siegel RL, Miller KD and Jemal A: Cancer statistics, 2016. CA Cancer J Clin 66: 7-30, 2016.

2. Siegel R, Ma J, Zou Z and Jemal A: Cancer statistics, 2014. CA Cancer J Clin 64: 9-29, 2014.

3. Miller KD, Siegel RL, Lin CC, Mariotto AB, Kramer JL, Rowland JH, Stein KD, Alteri R and Jemal A: Cancer treatment and survivorship statistics, 2016. CA Cancer J Clin 66: 271-289, 2016.

4. Weiss SA, Hanniford D, Hernando E and Osman I: Revisiting determinants of prognosis in cutaneous melanoma. Cancer 121: 4108-4123, 2015

5. Zainulabadeen A, Yao P and Zare H: Underexpression of specific interferon genes is associated with poor prognosis of melanoma. PLoS One 12: e0170025, 2017.

6. Tiffen J, Wilson S, Gallagher SJ, Hersey P and Filipp FV: Somatic copy number amplification and hyperactivating somatic mutations of EZH2 correlate with DNA methylation and drive epigenetic silencing of genes involved in tumor suppression and immune responses in melanoma. Neoplasia 18: 121-132, 2016.

7. Kim BH, Shenoy AR, Kumar P, Bradfield CJ and MacMicking JD: IFN-inducible GTPases in host cell defense. Cell Host Microbe 12: 432-444, 2012.

8. Hotter D, Sauter D and Kirchhoff F: Guanylate binding protein 5: Impairing virion infectivity by targeting retroviral envelope glycoproteins. Small GTPases 8: 31-37, 2017.

9. Goo YH, Son SH, Yechoor VK and Paul A: Transcriptional profiling of foam cells reveals induction of guanylate-binding proteins following western diet acceleration of atherosclerosis in the absence of global changes in inflammation. J Am Heart Assoc 5: e002663, 2016.

10. Tripal P, Bauer M, Naschberger E, Mörtinger T, Hohenadl C, Cornali E, Thurau M and Stürzl M: Unique features of different members of the human guanylate-binding protein family. J Interferon Cytokine Res 27: 44-52, 2007.

11. Degrandi D, Konermann C, Beuter-Gunia C, Kresse A, Würthner J, Kurig S, Beer $S$ and Pfeffer $K$ : Extensive characterization of IFN-induced GTPases mGBP1 to mGBP10 involved in host defense. J Immunol 179: 7729-7740, 2007

12. Vestal DJ and Jeyaratnam JA: The guanylate-binding proteins: Emerging insights into the biochemical properties and functions of this family of large interferon-induced guanosine triphosphatase. J Interferon Cytokine Res 31: 89-97, 2011.

13. Shenoy AR, Wellington DA, Kumar P, Kassa H, Booth CJ, Cresswell $\mathrm{P}$ and MacMicking JD: GBP5 promotes NLRP3 inflammasome assembly and immunity in mammals. Science 336: 481-485, 2012.

14. Friedman K, Brodsky AS, Lu S, Wood S, Gill AJ, Lombardo K, Yang D and Resnick MB: Medullary carcinoma of the colon: A distinct morphology reveals a distinctive immunoregulatory microenvironment. Mod Pathol 29: 528-541, 2016.

15. Britzen-LaurentN,LipnikK,OckerM,NaschbergerE,SchellererVS, Croner RS, Vieth M, Waldner M, Steinberg P, Hohenadl C and Stürzl M: GBP-1 acts as a tumor suppressor in colorectal cancer cells. Carcinogenesis 34: 153-162, 2013.

16. Britzen-Laurent N, Herrmann C, Naschberger E, Croner RS and Stürzl M: Pathophysiological role of guanylate-binding proteins in gastrointestinal diseases. World J Gastroenterol 22: 6434-6443, 2016.
17. Naschberger E, Croner RS, Merkel S, Dimmler A, Tripal P, Amann KU, Kremmer E, Brueckl WM, Papadopoulos T, Hohenadl C, et al: Angiostatic immune reaction in colorectal carcinoma: Impact on survival and perspectives for antiangiogenic therapy. Int J Cancer 123: 2120-2129, 2008.

18. Godoy P, Cadenas C, Hellwig B, Marchan R, Stewart J, Reif R, Lohr M, Gehrmann M, Rahnenführer J, Schmidt $M$ and Hengstler JG: Interferon-inducible guanylate binding protein (GBP2) is associated with better prognosis in breast cancer and indicates an efficient T cell response. Breast Cancer 21: 491-499, 2014

19. Lipnik K, Naschberger E, Gonin-Laurent N, Kodajova P, Petznek H, Rungaldier S, Astigiano S, Ferrini S, Stürzl M and Hohenadl C: Interferon gamma-induced human guanylate binding protein 1 inhibits mammary tumor growth in mice. Mol Med 16: 177-187, 2010.

20. Yu CJ, Chang KP, Chang YJ, Hsu CW, Liang Y, Yu JS, Chi LM, Chang YS and Wu CC: Identification of guanylate-binding protein 1 as a potential oral cancer marker involved in cell invasion using omics-based analysis. J Proteome Res 10: 3778-3788, 2011

21. Guimarães DP, Oliveira IM, de Moraes E, Paiva GR, Souza DM, Barnas C,Olmedo DB,PintoCE,Faria PA,De Moura GalloCV, et al: Interferon-inducible guanylate binding protein (GBP)-2: A novel p53-regulated tumor marker in esophageal squamous cell carcinomas. Int J Cancer 124: 272-279, 2009.

22. Fellenberg F, Hartmann TB, Dummer R, Usener D, Schadendorf D and Eichmüller S: GBP-5 splicing variants: New guanylate-binding proteins with tumor-associated expression and antigenicity. J Invest Dermatol 122: 1510-1517, 2004.

23. Persano L, Moserle L, Esposito G, Bronte V, Barbieri V, Iafrate M, Gardiman MP, Larghero P, Pfeffer U, Naschberger E, et al: Interferon-alpha counteracts the angiogenic switch and reduces tumor cell proliferation in a spontaneous model of prostatic cancer. Carcinogenesis 30: 851-860, 2009.

24. Lubeseder-Martellato C, Guenzi E, Jörg A, Töpolt K, Naschberger E, Kremmer E, Zietz C, Tschachler E, Hutzler P, Schwemmle M, et al: Guanylate-binding protein-1 expression is selectively induced by inflammatory cytokines and is an activation marker of endothelial cells during inflammatory diseases. Am J Pathol 161: 1749-1759, 2002.

25. Guenzi E, Töpolt K, Cornali E, Lubeseder-Martellato C, Jörg A, Matzen K, Zietz C, Kremmer E, Nappi F, Schwemmle M, et al: The helical domain of GBP-1 mediates the inhibition of endothelial cell proliferation by inflammatory cytokines. EMBO J 20: 5568-5577, 2001

26. Cheng YS, Colonno RJ and Yin FH: Interferon induction of fibroblast proteins with guanylate binding activity. J Biol Chem 258: 7746-7750, 1983.

27. Anaya J: OncoLnc: Linking TCGA survival data to mRNAs, miRNAs, and lncRNAs. Peer J Comput Sci 2: e67, 2016.

28. Shaul YD, Yuan B, Thiru P, Nutter-Upham A, McCallum S, Lanzkron C, Bell GW and Sabatini DM: MERAV: A tool for comparing gene expression across human tissues and cell types. Nucleic Acids Res 44: D560-D566, 2016.

29. Carithers LJ, Ardlie K, Barcus M, Branton PA, Britton A, Buia SA, Compton CC,DeLuca DS,Peter-DemchokJ,GelfandET, et al: A novel approach to high-quality postmortem tissue procurement: The GTEx project. Biopreserv Biobank 13: 311-319, 2015.

30. Warde-Farley D, Donaldson SL, Comes O, Zuberi K, Badrawi R, Chao P, Franz M, Grouios C, Kazi F, Lopes CT, et al: The GeneMANIA prediction server: Biological network integration for gene prioritization and predicting gene function. Nucleic Acids Res 38 (Web Server Issue): W214-W220, 2010.

31. Huang da W, Sherman BT and Lempicki RA: Bioinformatics enrichment tools: Paths toward the comprehensive functional analysis of large gene lists. Nucleic Acids Res 37: 1-13, 2009.

32. Huang da W, Sherman BT and Lempicki RA: Systematic and integrative analysis of large gene lists using DAVID bioinformatics resources. Nat Protoc 4: 44-57, 2009.

33. Olszewski MA, Gray J and Vestal DJ: In silico genomic analysis of the human and murine guanylate-binding protein (GBP) gene clusters. J Interferon Cytokine Res 26: 328-352, 2006.

34. Britzen-Laurent N, Bauer M, Berton V, Fischer N, Syguda A, Reipschläger S, Naschberger E, Herrmann C and Stürzl M: Intracellular trafficking of guanylate-binding proteins is regulated by heterodimerization in a hierarchical manner. PLoS One 5: e14246, 2010.

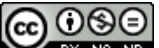

This work is licensed under a Creative Commons Attribution-NonCommercial-NoDerivatives 4.0 International (CC BY-NC-ND 4.0) License. 